Mediterranean Azadinium dexteroporum (Dinophyceae) produces six novel azaspiracids and azaspiracid-35: a structural study by a multi-platform mass spectrometry approach

Rachele Rossi, Carmela Dell'Aversano, Bernd Krock, Patrizia Ciminiello, Isabella Percopo, Urban Tillmann, Vittorio Soprano, et al.

Analytical and Bioanalytical Chemistry

ISSN 1618-2642

Volume 409

Number 4

Anal Bioanal Chem (2017)

409:1121-1134

DOI 10.1007/s00216-016-0037-4

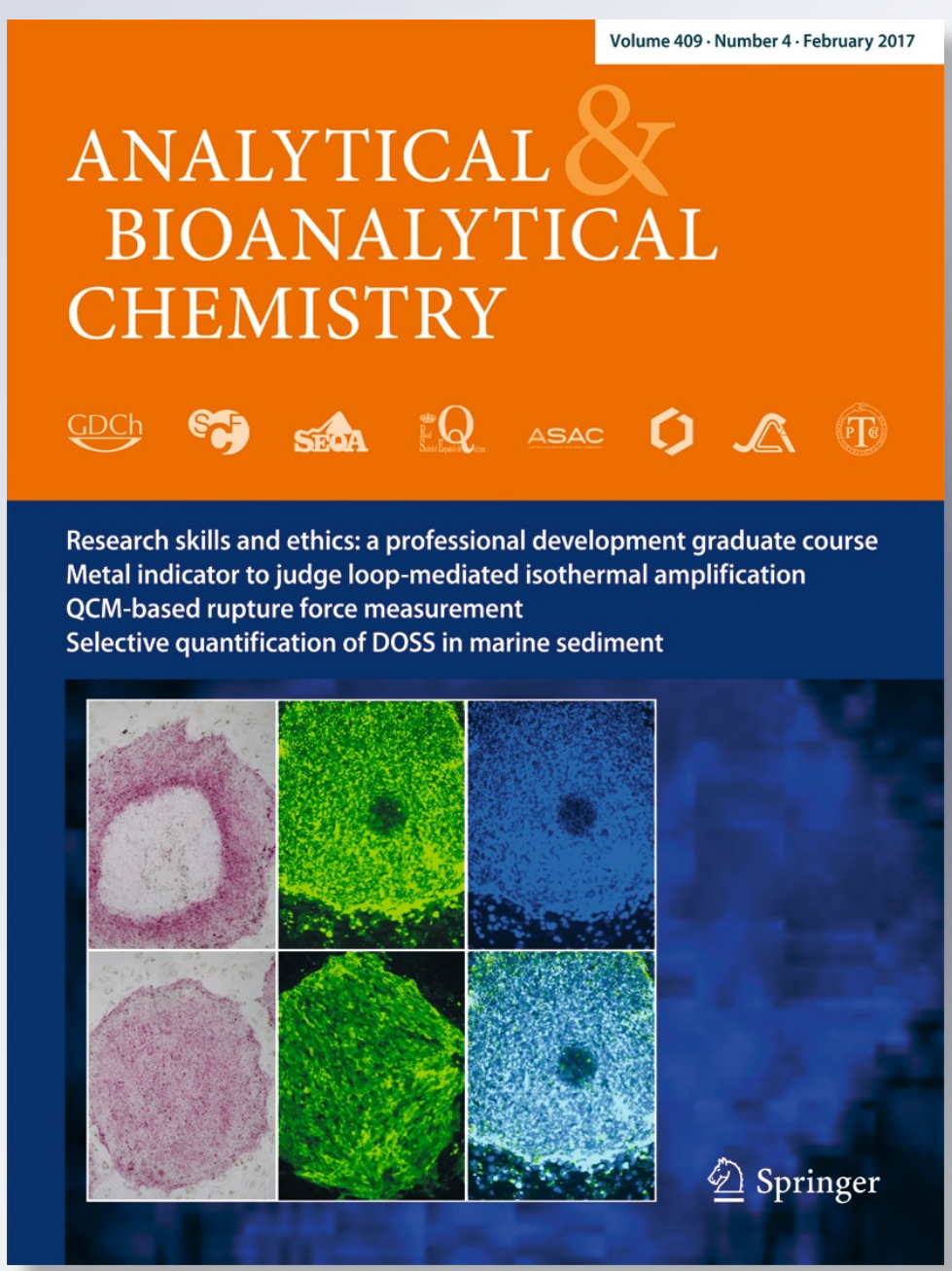

望 Springer 
Your article is protected by copyright and all rights are held exclusively by SpringerVerlag Berlin Heidelberg. This e-offprint is for personal use only and shall not be selfarchived in electronic repositories. If you wish to self-archive your article, please use the accepted manuscript version for posting on your own website. You may further deposit the accepted manuscript version in any repository, provided it is only made publicly available 12 months after official publication or later and provided acknowledgement is given to the original source of publication and a link is inserted to the published article on Springer's website. The link must be accompanied by the following text: "The final publication is available at link.springer.com". 


\title{
Mediterranean Azadinium dexteroporum (Dinophyceae) produces six novel azaspiracids and azaspiracid-35: a structural study by a multi-platform mass spectrometry approach
}

\author{
Rachele Rossi $^{1}$ - Carmela Dell'Aversano ${ }^{2}$ - Bernd Krock ${ }^{3}$ - Patrizia Ciminiello ${ }^{2}$. \\ Isabella Percopo $^{4} \cdot$ Urban Tillmann $^{3} \cdot$ Vittorio Soprano $^{1} \cdot$ Adriana Zingone $^{4}$
}

Received: 28 July 2016/Revised: 11 October 2016/Accepted: 17 October 2016/Published online: 7 November 2016

(C) Springer-Verlag Berlin Heidelberg 2016

\begin{abstract}
Azadinium dexteroporum is the first species of the genus described from the Mediterranean Sea and it produces different azaspiracids (AZA). The aims of this work were to characterize the toxin profile of the species and gain structural information on azaspiracids produced by the $A$. dexteroporum strain SZN-B848 isolated from the Gulf of Naples. Liquid chromatography-mass spectrometry (LC-MS) analyses were carried out on three MS systems having different ion source geometries (ESI, TurboIonSpray®, ESI ION MAX) and different MS analyzers operating either at unit resolution or at high resolution, namely a hybrid triple quadrupole-linear ion trap (Q-Trap MS), a time of flight (TOF MS), and a hybrid linear ion trap Orbitrap XL Fourier transform mass spectrometer (LTQ Orbitrap XL FTMS). As a combined result of these different analyses, A. dexteroporum showed to produce AZA-
\end{abstract}

Rachele Rossi and Carmela Dell'Aversano contributed equally to this work.

Electronic supplementary material The online version of this article (doi:10.1007/s00216-016-0037-4) contains supplementary material, which is available to authorized users.

Carmela Dell'Aversano

dellaver@unina.it

$\triangle$ Adriana Zingone

zingone@szn.it

1 Istituto Zooprofilattico Sperimentale del Mezzogiorno, Via Salute 2, 80055 Portici, Italy

2 Department of Pharmacy, University of Napoli Federico II, Via D. Montesano 49, 80131 Napoli, Italy

3 Alfred-Wegener-Institut, Helmholtz-Zentrum für Polar- und Meeresforschung, Am Handelshafen 12,

27570 Bremerhaven, Germany

4 Department of Integrative Marine Ecology, Stazione Zoologica Anton Dohrn, Villa Comunale, 80121 Napoli, Italy
35, previously reported from Azadinium spinosum, and six compounds that represent new additions to the AZA-group of toxins, including AZA-54 to AZA-58 and 3-epiAZA-7, a stereoisomer of the shellfish metabolite AZA-7. Based on the interpretation of fragmentation patterns, we propose that all these molecules, except AZA-55, have the same A to I ring system as AZA-1, with structural modifications all located in the carboxylic side chain. Considering that none of the azaspiracids produced by the Mediterranean strain of A. dexteroporum is currently regulated by European food safety authorities, monitoring programs of marine biotoxins in the Mediterranean area should take into account the occurrence of the new analogues to avoid an underestimation of the AZArelated risk for seafood consumers.

Keywords Azaspiracids · Azadinium dexteroporum $\cdot$ Marine toxins $\cdot$ LC-MS/MS $\cdot$ LC-HRMS $^{n} \cdot$ LC-TOFMS

\section{Introduction}

Azaspiracids (AZAs) are a group of polyether toxins first reported to cause seafood poisoning in the Netherlands in 1995, following the ingestion of contaminated shellfish from Killary Harbour, Ireland [1]. Shellfish were contaminated by a unique marine toxin, originally named "Killary-toxin" and shortly after structurally elucidated and renamed azaspiracid-1 (AZA-1) [2-4] (Fig. 1). The name was consistent with its chemical features which includes a six-membered cyclic amine (AZA), a unique tri-spiro assembly (SPIRO), and a carboxylic acid group (ACID). The rest of the molecule consisted of a linear carbon chain cyclized at several points through ether bridges. The biogenetic origin of azaspiracids causing the Killary Harbour shellfish contamination was initially identified in the heterotrophic dinoflagellates 
Fig. 1 Planar structure of AZA-1 and characteristic fragmentations occurring in CID mode. The other azaspiracids so far known mainly differ from AZA-1 by substitution at $\mathrm{C} 3(\mathrm{H}$ or $\mathrm{OH}), \mathrm{C} 8\left(\mathrm{H}\right.$ or $\left.\mathrm{CH}_{3}\right)$, $\mathrm{C} 21\left(\mathrm{OH}\right.$ or $\left.\mathrm{OCH}_{3}\right), \mathrm{C} 22(\mathrm{H}$, $\mathrm{CH}_{3}$, or $\left.\mathrm{COOH}\right), \mathrm{C} 23(\mathrm{H}$ or $\mathrm{OH})$, and/or $\mathrm{C} 39\left(\mathrm{H}\right.$ or $\left.\mathrm{CH}_{3}\right)$

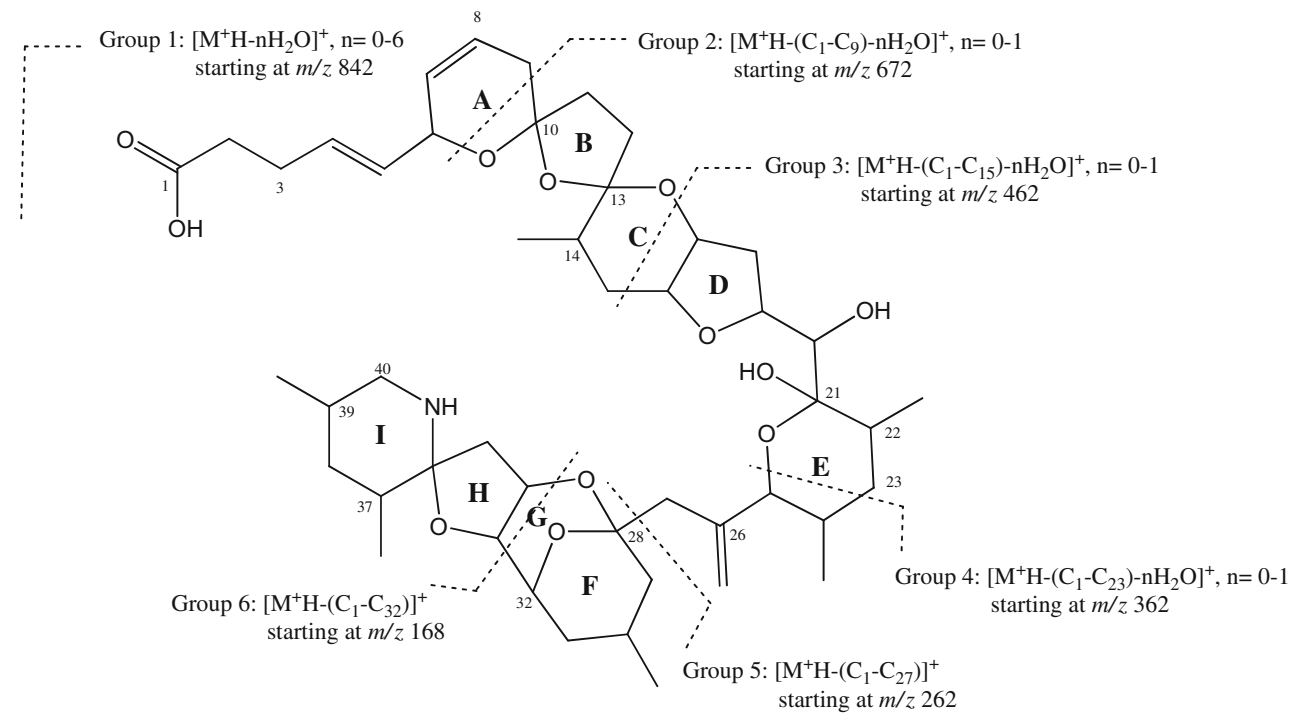

AZA-1
Protoperidinium crassipes [5], but was later definitely proven to be the phototrophic dinoflagellate Azadinium spinosum [6].

Over the last years, several analogues of AZA-1 have been discovered either in shellfish [7-11] or in dinoflagellates [6, 12-17] and structurally characterized by tandem mass spectrometry (MS/MS) and partly also by nuclear magnetic resonance (NMR) spectroscopy. Some AZAs (AZA-1 and AZA2 , among others) are actually produced by the dinoflagellates, whereas others (e.g., AZA-3 to AZA-19) seem to derive from biotransformation occurring in shellfish [9]. The formation of extraction artifacts (21-epi-AZA-1, AZA-29, AZA-30, and AZA-32) has also been demonstrated [18], especially when methanol is used as extraction solvent. Consequently, the extraction solvent currently suggested for AZA analysis is acetone or aqueous acetonitrile. Not considering stereoisomers, more than 30 variants of AZAs have been detected so far [19, 20]. Among them, only AZA-1, AZA-2, and AZA-3 are currently regulated in Europe and hence regularly monitored in shellfish to safeguard seafood consumer health [21].

The official technique for the monitoring of regulated azaspiracids in shellfish is LC-MS [22] which provides quantitative data and is also widely used in research settings to gain structural insights into so far unknown molecules. The MS behavior of AZAs is indeed characteristic and it has been studied widely using either tandem MS or high resolution MS analyzers [9, 23-25]. Over the last years, new dinophycean species other than $A$. spinosum have been identified as AZA producers, including Amphidoma languida from Bantry Bay and two species in the genus Azadinium, i.e., Azadinium poporum from the North Sea, Korea [12], and the China Sea [26], and Azadinium dexteroporum from the Mediterranean Sea [13]. The latter species, first described based on a strain isolated in the Gulf of Naples [13], was later retrieved in Arctic waters [27], but the cold water strain slightly differed in molecular sequence data and did not produce any AZA. Preliminary LC-TOF MS analysis of an $80 \%$ aqueous methanol extract from the Mediterranean A. dexteroporum strain showed the presence of three potentially new AZA-like compounds with $[\mathrm{M}+\mathrm{H}]^{+}$ions at $\mathrm{m} / \mathrm{z} 828, \mathrm{~m} / \mathrm{z} 858$, and $\mathrm{m} / \mathrm{z}$ 830 [13]. These compounds were supposed to be AZA-like compounds, based on their molecular masses and in-source fragmentation behavior analyzed in comparison to that of AZA-1, and tentatively assigned to putative AZA-3, AZA-7, and Compound 3 [12], respectively, while several other AZAlike compounds were noticed and left undescribed.

The aim of this work was to further investigate AZAs produced by the Mediterranean A. dexteroporum SZN-B848 strain to shed light on their identity, thus providing a better characterization of the whole toxin profile of the strain. The analyses took advantage of several different LC-MS techniques, used in combination in order to obtain structural information on the AZAs produced by this strain.

\section{Materials and methods}

\section{Chemicals and standards}

Water was deionized and purified through a MilliQ water purification system (Milli-Q, Millipore, Eschborn, Germany) to $18 \mathrm{M} \Omega \mathrm{cm}^{-1}$ or better quality. The organic solvents acetonitrile and methanol (HPLC grade) and the additives formic acid (90\%, p.a.), acetic acid (p.a.), and ammonium formate (p.a.) were purchased from Sigma-Aldrich (Steinheim, Germany) and Merck (Darmstadt, Germany). Certified reference material of AZA-1 was purchased from NRC, Canada (NRC CRM 
AZA-1) and used for setting LC-HRMS ${ }^{n}$ conditions and for quantitative analysis. A mussel tissue extract containing AZA1, AZA-2, and AZA-3, kindly provided by Dr Philipp Hess (Ifremer, Nantes, France), and reference samples of AZA-7 and AZA-35, kindly provided by Dr Jane Kilkoyne (Marine Institute, Galway, Ireland), were used for toxins identification.

\section{A. dexteroporum batch cultures}

The strain SZN-B848 of A. dexteroporum was isolated from a water sample collected on May 11, 2010 at the LTER-MC in the Gulf of Naples. The culture was grown in $1 \mathrm{~L}$ Erlenmeyer flask in $\mathrm{K} / 10$ medium at a salinity of 36 , under no axenic conditions. It was maintained at $20^{\circ} \mathrm{C}$ under an irradiance of $70-80 \mu \mathrm{mol}$ photons $\mathrm{m}^{-2} \mathrm{~s}^{-1}$ in a $12: 12$ light/dark regime as described in Percopo et al. [13]. Cell density in the culture harvested for chemical analyses during the stationary growth phase was $1.4 \times 10^{5}$ cells $\mathrm{mL}^{-1}$.

\section{Extraction}

The $80 \%$ aqueous $\mathrm{MeOH}$ extract of $A$. dexteroporum used in Percopo et al. [13] was re-analyzed by LC-MS 6 months after preparation. Considering that extraction with aqueous methanol may lead to formation of AZAs artifacts, including methyl esters and/or methyl ketals [18], another batch of A. dexteroporum was extracted using the procedure described by Jauffrais et al. [18]. In particular, the pellet $\left(1.4 \times 10^{5}\right.$ cells $)$ was suspended in $1 \mathrm{~mL}$ acetone $/ \mathrm{H}_{2} \mathrm{O}(9: 1, v / v)$, vortexed for $1 \mathrm{~min}$, sonicated for $10 \mathrm{~min}$, and centrifuged at $1000 \times \mathrm{g}$ for $5 \mathrm{~min}$. The supernatant was transferred into a glass test tube and the pellet was re-extracted twice with $0.5 \mathrm{~mL}$ of acetone/ $\mathrm{H}_{2} \mathrm{O}(9: 1, v / v)$ following the same procedure. The supernatants were combined and evaporated to dryness. The residue was dissolved in $1 \mathrm{~mL}$ acetone $/ \mathrm{H}_{2} \mathrm{O}(9: 1, v / v)$, centrifuged through a $0.22-\mu \mathrm{m}$ spin-filter (Millipore Ultrafree, Eschborn, Germany) at $3000 \times g$ for $5 \mathrm{~min}$, and directly analyzed by LCMS on system \#1 and subsequently on systems \#2 and \#3.

\section{Liquid chromatography-mass spectrometry (LC-MS) analyses}

LC-MS analyses were performed according to Quilliam et al. [28] on three different systems, namely a LC-Time of Flight MS (LC-TOFMS) (system \#1), a LC-LTQ Orbitrap XL FTMS (LC-HRMS ${ }^{n}, n=1-3$ ) (system \#2), and a LC-triple quadrupole MS (LC-MS/MS) (system \#3). A Luna $3 \mu \mathrm{C}(8) 150 \times$ $2.00 \mathrm{~mm}$ (system \#1) and a Hypersil $3 \mu$ C8 BDS, $50 \times$ $2.00 \mathrm{~mm}$ columns (Phenomenex, Torrance, CA, USA) (systems \#2 and \#3) were kept at room temperature and eluted with water (eluent A) and $95 \%$ acetonitrile/water (eluent B), both containing $50 \mathrm{mM}$ formic acid and $2 \mathrm{mM}$ ammonium formate. Flow rate was $200 \mu \mathrm{L} \mathrm{min}{ }^{-1}$ and injection volume was $5 \mu \mathrm{L}$. MS parameters and gradient conditions on systems \#1-3 are detailed below.

System \#1 LC-TOF MS analyses were performed at IZSM (Italy) on an Agilent TOF MS model G1969 coupled with an Agilent model 1100 LC (Agilent Palo Alto, CA, USA). The following linear gradient was used: $60 \%$ B for $6 \mathrm{~min}, 60$ to $80 \% \mathrm{~B}$ in $0.5 \mathrm{~min}$ and hold for $2 \mathrm{~min}$, then returning to initial conditions in $6 \mathrm{~min}$. Full scan MS experiments (positive ion mode) were performed in the mass range $m / z, 100-1000$ at a resolving power $(\mathrm{RP})=10,000$. The following ESI source settings were used: drying gas $\left(\mathrm{N}_{2}\right)$ flow rate $=8 \mathrm{~mL} \mathrm{~min}{ }^{-1}$, drying gas temperature $=350{ }^{\circ} \mathrm{C}$, nebulizer gas $=45 \mathrm{psi}$, capillary voltage $=4000 \mathrm{~V}$, fragmentor voltage $=350 \mathrm{~V}$, skimmer voltage $=60 \mathrm{~V}$. A tuning mix (G1969-85001) was used for lock mass calibration. Agilent LC/MS-TOF Software was used for data acquisition and data processing by analyzing all the scans ("walking on the chromatogram") and identifying the characteristic fragment ions in the spectrum preview. Extracted ion chromatograms (EIC) were obtained for all the AZAs by selecting exact masses of their $[\mathrm{M}+\mathrm{H}]^{+}$ions at a mass tolerance of $10 \mathrm{ppm}$.

System \#2 LC-HRMS ${ }^{n}$ analyses $(n=1-3)$ were performed at University of Napoli Federico II (Italy) on a hybrid linear ion trap LTQ Orbitrap XLTM Fourier Transform Mass Spectrometer (FTMS) equipped with an ESI ION MAX ${ }^{\mathrm{TM}}$ source (Thermo Fisher, San José, USA) and coupled to an Agilent 1100 LC binary system (Agilent Palo Alto, CA, USA). The following gradient elution was used, 30 to $100 \% \mathrm{~B}$ in $15 \mathrm{~min}$ followed by $100 \% \mathrm{~B}$ for $9 \mathrm{~min}$, then returning to initial conditions until $27 \mathrm{~min}$, and reequilibrating for $9 \mathrm{~min}$ (total run time $=36 \mathrm{~min}$ ). Full scan HRMS experiments (positive ion mode) were acquired in the $m / z, 700-900$ range at a $\mathrm{RP}=60,000(\mathrm{FWHM}$ at $m / z$ 400). The following source settings were used: spray voltage $=4.8 \mathrm{kV}$, capillary temperature $=260{ }^{\circ} \mathrm{C}$, capillary voltage $=29 \mathrm{~V}$, sheath gas flow $=36$ and auxiliary gas flow $=14$ (arbitrary units), tube lens voltage $=125 \mathrm{~V} . \mathrm{HRMS}^{n}$ experiments $(n=2$, 3) were acquired at RP $=30,000$ using either higher energy collisional dissociation (HCD), collision-induced dissociation (CID), or their combinations (CID/CID and CID/HCD). In HR HCD $\mathrm{MS}^{2}$ experiments $[\mathrm{M}+\mathrm{H}]^{+}$ions of individual AZAs were used as precursors with a collision energy (CE) $=35 \%$. In HR CID/CID $\mathrm{MS}^{3}$ and HR CID/HCD MS ${ }^{3}$ experiments, precursors were $[\mathrm{M}+\mathrm{H}]^{+}$ions $(\mathrm{CE}=45 \%)$ and $[\mathrm{M}+\mathrm{H}-$ $\left.\mathrm{H}_{2} \mathrm{O}\right]^{+}$ions $(\mathrm{CE}=35 \%)$. An isolation width $(\mathrm{IW})=2.0 \mathrm{Da}$, an activation $\mathrm{Q}=0.250$, and an activation time $=30 \mathrm{~ms}$ were used. Calculation of elemental formulae was performed on the mono-isotopic peak of each ion cluster using Xcalibur software v2.0.7 with a mass tolerance of 3 to $5 \mathrm{ppm}$. The isotopic ion pattern was taken into account in assigning molecular formula. EIC for the detected AZAs were obtained by 
selecting the $[\mathrm{M}+\mathrm{H}]^{+}$ion clusters and setting mass tolerance to a value compatible with the error in ion assignment of the AZA standard (1-4 ppm) depending on the daily instrument calibration status.

System \#3 LC-MS/MS analyses were performed at AWI (Germany) on an AB-SCIEX-4000 Q-Trap MS equipped with a TurboSpray® interface coupled to an Agilent model 1100 LC. The LC equipment included a solvent reservoir, in-line degasser (G1379A), binary pump (G1311A), refrigerated autosampler (G1329A/G1330B), and temperature-controlled column oven (G1316A). The following gradient elution was used, 30 to $100 \% \mathrm{~B}$ in $8 \mathrm{~min}$ followed by $100 \% \mathrm{~B}$ for $10 \mathrm{~min}$, then returning to initial conditions until $21 \mathrm{~min}$ and reequilibrating for $8 \mathrm{~min}$ (total run time $=29 \mathrm{~min}$ ). In addition, a guard column (Securiguard, Phenomenex, Aschaffenburg, Germany) was used. AZA profiles were determined in one period $(0-18)$ min with curtain gas $=10 \mathrm{psi}, \mathrm{CAD}=$ medium, ion spray voltage $=5500 \mathrm{~V}$, temperature $=$ ambient, nebulizer gas $=10$ psi, auxiliary gas $=$ off, interface heater $=$ on, declustering potential $=100 \mathrm{~V}$, entrance potential $=10 \mathrm{~V}$, exit potential $=30 \mathrm{~V}$. Selected reaction monitoring $(\mathrm{SRM})$ experiments were carried out in positive ion mode by selecting the transitions (precursor ion $>$ fragment ion) shown in Table 1. AZAs were calibrated against AZA-1 CRM and expressed as AZA-1 equivalents. Precursor ion scanning (PI) experiments were carried in the positive ion mode scanning precursors of

Table 1 Mass transitions $m / z(\mathrm{Q} 1>\mathrm{Q} 3$ mass) and collision energy (CE) used to monitor azaspiracids in SRM experiments

\begin{tabular}{lll}
\hline Azaspiracid (AZA) & Mass transition & CE (V) \\
\hline AZA-33 & $716>698$ & 40 \\
AZA-39 & $816>798$ & 40 \\
AZA-39 & $816>348$ & 70 \\
AZA-3 & $828>658$ & 70 \\
AZA-3, AZA-58 & $828>810$ & 40 \\
AZA-35, AZA-38 & $830>812$ & 40 \\
AZA-38 & $830>348$ & 70 \\
AZA-1 & $842>672$ & 70 \\
AZA-1, AZA-6, AZA-41 & $842>824$ & 40 \\
AZA-4, AZA-5, AZA-56 & $844>826$ & 40 \\
AZA-37 & $846>828$ & 40 \\
AZA-2, Me-AZA-1 & $856>672$ & 70 \\
AZA-2, Me-AZA-1 & $856>838$ & 40 \\
AZA-7, AZA-8, AZA-9, AZA-10, AZA-36 & $858>840$ & 40 \\
AZA-36 & $858>348$ & 70 \\
AZA-55 & $868>362$ & 70 \\
AZA-54, Me-AZA-2 & $870>852$ & 40 \\
AZA-11, AZA-12 & $872>854$ & 40 \\
AZA-57 & $884>866$ & 40 \\
\hline & & \\
\hline
\end{tabular}

the group 4 fragments $m / z, 348, m / z, 360$, and $m / z, 362$ in the mass range $m / z$ 400-950 under the same ion source conditions reported above using collision energy $=70 \mathrm{~V}$ and exit potential $=12 \mathrm{~V}$. Product ion spectra were recorded in the enhanced product ion (EPI) mode in the mass range $\mathrm{m} / \mathrm{z}$ 150-930 under the same ion source conditions reported above using collision energy spread $=0,10 \mathrm{~V}$ and collision energy $=70 \mathrm{~V}$. Positive ionization and unit resolution mode were used.

\section{Quantitation}

Quantitation was performed on system \#3 by external calibration in single measurements against an AZA-1 CRM solution and all values were expressed as AZA-1 equivalents. Relative percentages of AZAs were measured based on peak areas of individual AZAs obtained in SRM experiments and crosschecked with EIC of individual AZAs obtained on system \#2. Cell quota was extrapolated from the data, assuming that the detected AZAs had the same molar response as AZA-1.

\section{Derivatization with diazomethane}

A 50- $\mu \mathrm{L}$ aliquot of the algal extract was mixed with an equal volume of a $2 \mathrm{M}$ trimethylsilyl diazomethane (TMSDM) solution (product no: 527524, Sigma-Aldrich, Steinheim, Germany). The mixture was vortexed six times every $5 \mathrm{~min}$ for complete mixing. After $30 \mathrm{~min}$, excess TMSDM was destroyed by the addition of $5 \mu \mathrm{L}$ glacial acetic acid and vortexing. The derivatized sample was taken to dryness in a gentle nitrogen stream and the residue taken up in $50 \mu \mathrm{L}$ methanol.

\section{Results and discussion}

The aqueous methanol extract studied by Percopo et al. [13] and an acetone extract of the same $A$. dexteroporum SZNB848 strain were analyzed by LC-MS on three MS systems having different ion source geometries (ESI, TurboIonSpray ${ }^{\circledR}$, ESI ION MAX) and different MS analyzers operating either at unit resolution or at high resolution (Q-Trap MS, TOF MS, and LTQ Orbitrap XL FTMS). Both extracts gave the same results confirming that none of the AZAs detected in the methanolic extract was an extraction artifact. Seven azaspiracids were detected (Fig. 2): AZA-35, which had been reported previously from A. spinosum [29], and six novel compounds that represent new addition to the AZAgroup of toxins, including AZA-54 to AZA-58 and 3-epiAZA-7, a stereoisomer of the shellfish metabolite AZA-7 [5]. A total AZA cell quota of $24.5 \mathrm{fg} / \mathrm{cell}$ was estimated from a cross check of the Q-Trap MS data with relative abundances and concentrations measured on the LTQ Orbitrap XL FTMS 


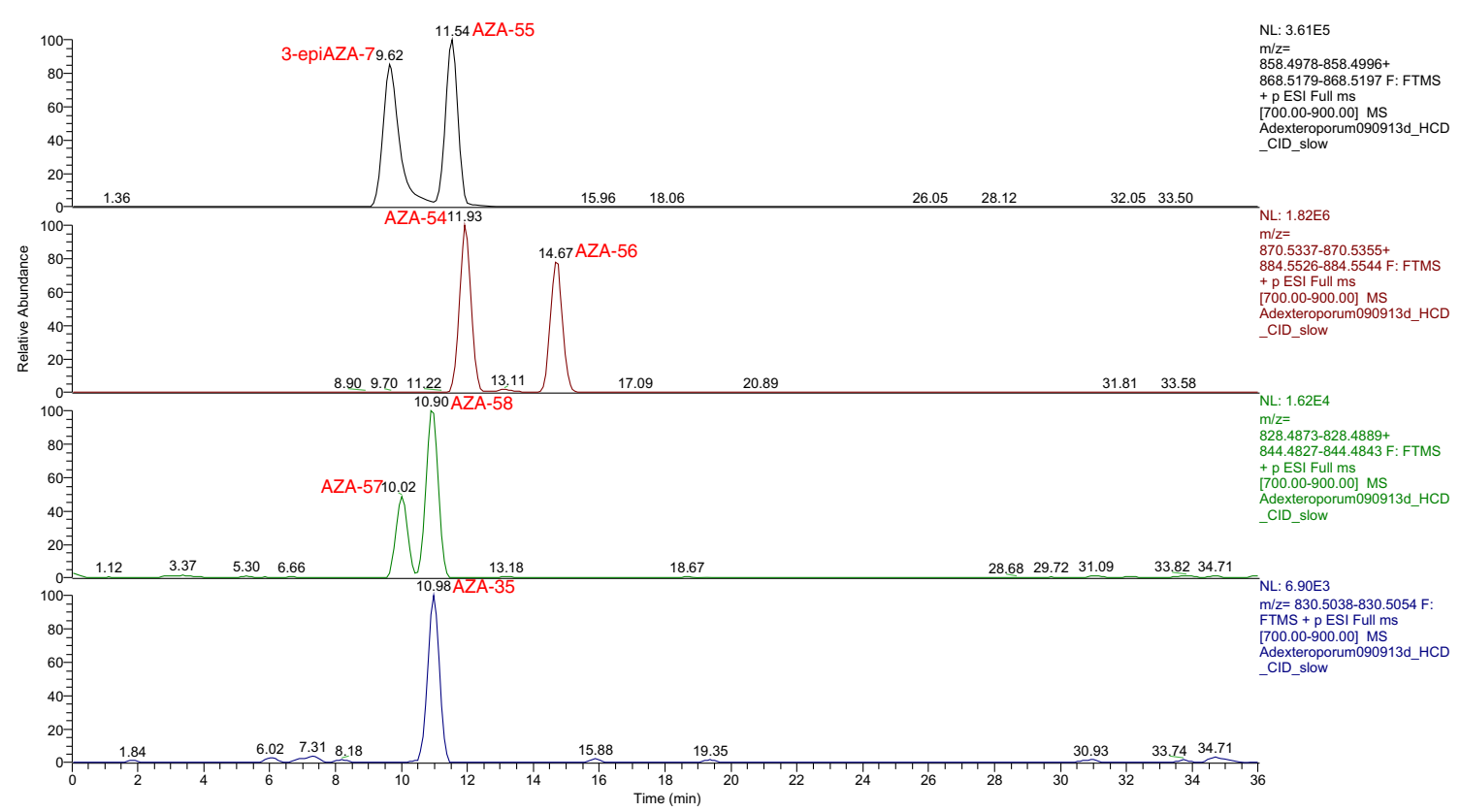

Fig. 2 LC-HRMS analysis (system \#2) of the Mediterranean A. dexteroporum strain. Extracted ion chromatograms (1 ppm mass tolerance, normalized peak height) of the seven azaspiracids contained in the acetone extract

using AZA-1 CRM as standard. This cell quota is comparable to that of other AZA-producing species such as A. spinosum (5-50 fg/cell) [6] and A. poporum (0-10 fg/cell) $[14,16]$ and is quite different from that reported by Percopo et al. (2-3 fg/ cell) for the same strain, based on TOF MS analyses of only three minor components of the A. dexteroporum profile [13].

The available material was not sufficient for even attempting isolation and subsequent full structural elucidation based on NMR spectroscopy. Thus, MS fragmentation analysis was the method of choice because of its sensitivity and ability to provide structural information on compounds contained at trace levels in crude extracts. AZA-1, which was not found in the A. dexteroporum extract, was used as reference for the comparative interpretation of the fragmentation patterns. It is worth mentioning that fragmentation of AZAs occurs by elimination of molecule portions of variable size from their charged end - the amine nitrogen in ring Iproducing group 1 fragments $\left[\mathrm{M}+\mathrm{H}-n \mathrm{H}_{2} \mathrm{O}\right]^{+}$with $n=1-6$ and several structurally informative fragment ions due to cleavages at specific sites of the polyketide chain, each generally undergoing multiple water losses (group 2-6 fragments) (Fig. 1). The main cleavages include the following:

(a) A pseudo retro Diels-Alder (RDA) reaction of ring A [9] leading to loss of the $\mathrm{C} 1-\mathrm{C} 9$ part structure with its substituents and formation of a fragment which, along with its water losses, results in the group 2 fragment cluster (starting at $m / z, 672$ in AZA-1).

(b) A cleavage of ring $\mathrm{C}$ leading to elimination of the $\mathrm{C} 1$ C15 part structure and formation of a fragment which, together with its water losses, gives the group 3 fragments (starting at $m / z, 462$ in AZA-1).

(c) A pseudo RDA of ring $\mathrm{E}$ where $\mathrm{C} 1-\mathrm{C} 23$ are eliminated resulting in the formation of fragment ions that barely undergo water losses, named group 4 fragments (starting at $m / z 362$ for AZA-1).

(d) A cleavage between $\mathrm{C} 27$ and $\mathrm{C} 28$ where $\mathrm{C} 1-\mathrm{C} 27$ are eliminated resulting in formation of group 5 fragments (at $m / z 262$ in AZA-1)

(e) A pseudo RDA of ring $G$ resulting in the formation of group 6 fragments (at $m / z, 168$ in AZA-1).

Apart from these general fragmentation patterns, 3-hydroxy-AZAs, such as AZA-36 and AZA-37-compounds 1 and 2 in [12] - present a typical fragmentation pathway in their CID spectra: in addition to group 1 fragments (common to all AZAs), their pseudomolecular ion also eliminates $\mathrm{CO}_{2}$ (44 Da) and several water molecules. The $\left[\mathrm{M}-\mathrm{CO}_{2}-n \mathrm{H}_{2} \mathrm{O}\right]^{+}$ $(n=1-3)$ fragments usually represent up to $20 \%$ of the intensity of the highest peak but are clearly visible and represent a key feature of all the 3-hydroxy-AZAs analyzed so far [19].

The AZAs produced by the A. dexteroporum SZN-B848 strain were first revealed by the in-source fragmentation spectra obtained on the TOF MS, which were dominated by the $[\mathrm{M}+\mathrm{H}]^{+}$ions of each analogue and relevant group 1 fragments. The structurally informative group 2-4 fragments presented very low intensity on this system and in some cases could hardly be distinguished from the background noise, while the group 5-6 fragments were not detected at all. Therefore, further analyses of the fragmentation patterns contained in 

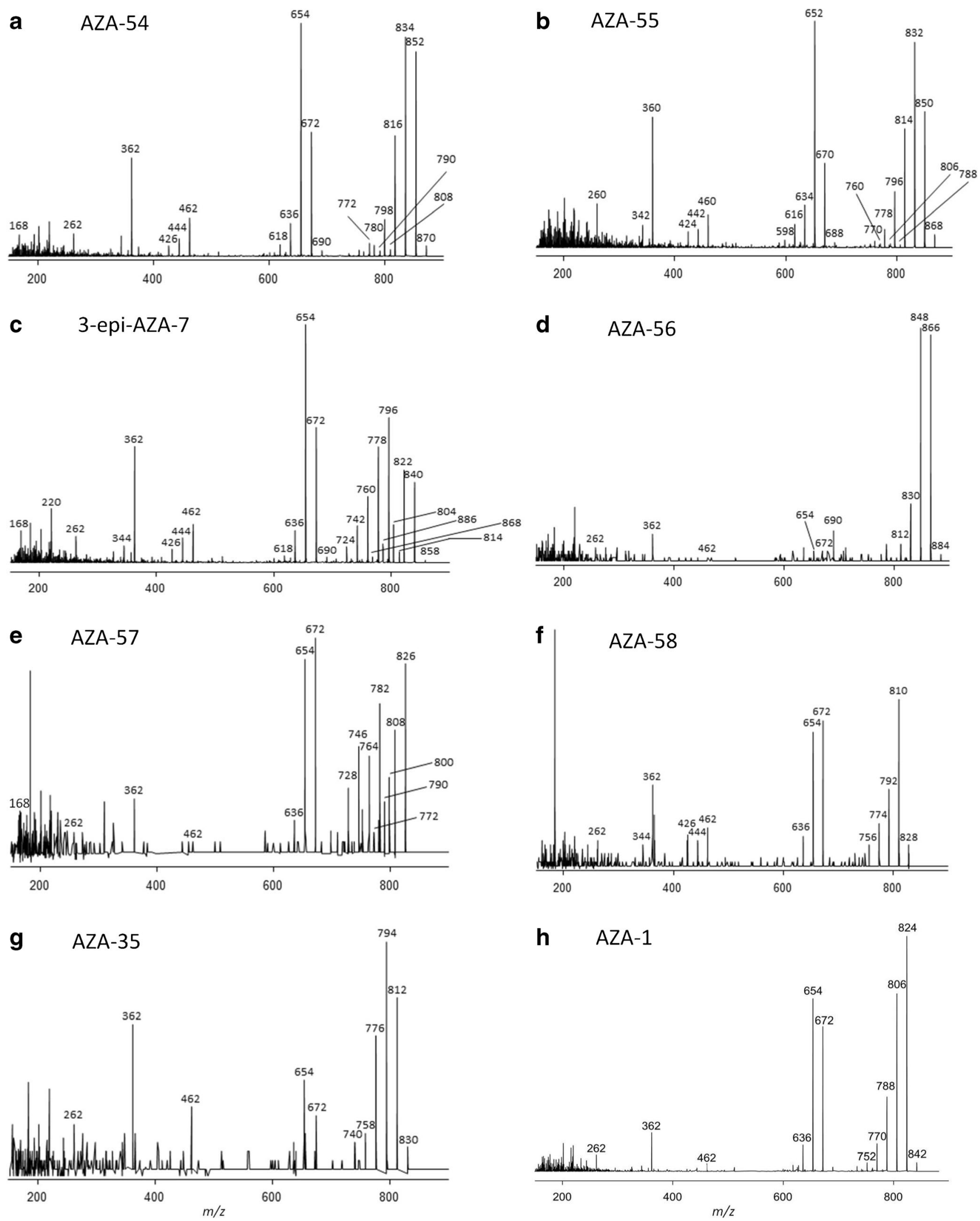

Fig. 3 CID spectra of the seven azaspiracid produced by the Mediterranean A. dexteroporum strain obtained on Q-Trap MS (system \#3). The highest labeled $\mathrm{m} / \mathrm{z}$, value in each CID spectrum refers to the $[\mathrm{M}+\mathrm{H}]^{+}$peak 
Table 2 Exact masses of the seven azaspiracids produced by the Mediterranean

A. dexteroporum strain and of AZA-1 standard measured on the LTQ-Orbitrap MS. Molecular formula (MF), ring double bond (RDB) equivalents, and errors $(\Delta$, $\mathrm{ppm})$ are also reported together with relative retention times (RRt) to AZA-1 obtained under the different chromatographic conditions (system \#1-3)

\begin{tabular}{llllllll}
\hline Name & {$[\mathrm{M}+\mathrm{H}]^{+}, m / z$} & Formula & RDB & $\Delta, \mathrm{ppm}$ & RRt \#1 & RRt \#2 & RRt \#3 \\
\hline AZA-54 & 870.5346 & $\mathrm{C}_{49} \mathrm{H}_{76} \mathrm{O}_{12} \mathrm{~N}$ & 12.5 & -1.553 & -3.93 & -0.71 & -0.61 \\
AZA-55 & 868.5188 & $\mathrm{C}_{49} \mathrm{H}_{74} \mathrm{O}_{12} \mathrm{~N}$ & 13.5 & -1.773 & -2.02 & -0.32 & -0.30 \\
3-epiAZA-7 & 858.4987 & $\mathrm{C}_{47} \mathrm{H}_{72} \mathrm{O}_{13} \mathrm{~N}$ & 12.5 & -1.068 & 2.83 & 1.60 & 0.94 \\
AZA-56 & 884.5535 & $\mathrm{C}_{50} \mathrm{H}_{78} \mathrm{O}_{12} \mathrm{~N}$ & 12.5 & 1.597 & -5.59 & -3.45 & -2.82 \\
AZA-57 & 844.4835 & $\mathrm{C}_{46} \mathrm{H}_{70} \mathrm{O}_{13} \mathrm{~N}$ & 12.5 & -0.688 & 1.96 & 1.2 & 0.65 \\
AZA-58 & 828.4881 & $\mathrm{C}_{46} \mathrm{H}_{70} \mathrm{O}_{12} \mathrm{~N}$ & 12.5 & -1.183 & -0.02 & 0.32 & 0.09 \\
AZA35 & 830.5046 & $\mathrm{C}_{46} \mathrm{H}_{72} \mathrm{O}_{12} \mathrm{~N}$ & 11.5 & -0.283 & -0.32 & 0.24 & 0 \\
AZA-1 & 842.50548 & $\mathrm{C}_{47} \mathrm{H}_{72} \mathrm{O}_{12} \mathrm{~N}$ & 12.5 & 0.685 & 7.24 & 11.22 & 12.09 \\
\hline
\end{tabular}

${ }^{\text {a }}$ Columns and gradients used for the chromatographic separation on systems \#1 (TOF MS), \#2 (LTQ Orbitrap XL FTMS), and \#3 (Q-Trap MS) are reported in the experimental section
CID MS spectra obtained on the Q-Trap MS (Fig. 3) and $\operatorname{HRMS}^{n}(n=1,2$, and 3) spectra obtained on the LTQOrbitrap FTMS (Tables 2, 3, and 4) were needed to gain confirmation of the structural features of the analogues.

LC-HRMS experiments on the LTQ Orbitrap XL allowed to assign molecular formula and ring double bond (RDB) equivalents to each of the seven AZAs contained in the A. dexteroporum extract (Table 2). The fragmentation pattern of each compound was studied through the analysis of LCHRMS $^{2}$ spectra in HCD mode and confirmed through LCHRMS $^{3}$ spectra in CID/CID or CID/HCD modes (Tables 3 and 4). HCD fragmentation mode provided spectra containing all the expected group 1-6 fragments, with the fragments in the low mass range being the most intense ones (see Electronic Supplementary Material (ESM), Fig. S1). However, for structural characterization of the minor

Table 3 Fragmentation pattern of 3-epiAZA-7 and AZA-35 produced by the Mediterranean A. dexteroporum strain versus that of AZA-1 standard measured on the LTQ-Orbitrap FTMS in various $\mathrm{HRMS}^{n}$ modes ( $n=2,3$ either $\mathrm{HCD}, \mathrm{CID} / \mathrm{HCD}$, or CID/CID). Errors in ion assignments were in the range $0.5-4 \mathrm{ppm}$

\begin{tabular}{|c|c|c|c|c|c|c|c|c|c|c|}
\hline & \multirow[b]{2}{*}{ Loss } & \multicolumn{3}{|l|}{ AZA-1 } & \multicolumn{3}{|c|}{ 3-epiAZA-7 } & \multicolumn{3}{|l|}{ AZA-35 } \\
\hline & & $m / z$ & Formula & $\mathrm{RDB}$ & $m / z$ & Formula & $\mathrm{RDB}$ & $m / z$ & Formula & RDB \\
\hline \multirow[t]{12}{*}{ Precursor } & & 842.5 & C47 H72 O12 N & 12.5 & 858.5 & C47 H72 O13 N & & 830.5 & C46 H72 O12 N & \\
\hline & $-1 \mathrm{H} 2 \mathrm{O}$ & 824.4917 & C47 H70 O11 N & 13.5 & 840.4897 & C47 H70 O12 N & 13.5 & & & \\
\hline & $-2 \mathrm{H} 2 \mathrm{O}$ & 806.4813 & C47 H68 O10 N & 14.5 & 822.4763 & C47 H68 O11 N & 14.5 & 794.4797 & C46 H68 O10 N & 13.5 \\
\hline & $-3 \mathrm{H} 2 \mathrm{O}$ & 788.4713 & C47 H66 O9 N & 15.5 & 804.4660 & C47 H66 O10 N & 15.5 & 776.4702 & C46 H66 O9 N & 14.5 \\
\hline & $-4 \mathrm{H} 2 \mathrm{O}$ & 770.4616 & C47 H64 O8 N & 16.5 & & & & 758.4598 & C46 H64 O8 N & 15.5 \\
\hline & $-5 \mathrm{H} 2 \mathrm{O}$ & 752.4512 & C47 H62 O7 N & 17.5 & & & & & & \\
\hline & $-6 \mathrm{H} 2 \mathrm{O}$ & 734.4421 & C47 H60 O6 N & 18.5 & & & & & & \\
\hline & $-\mathrm{CO} 2-\mathrm{H} 2 \mathrm{O}$ & & & & 796.4974 & C46 H70 O10 N & 12.5 & & & \\
\hline & $-\mathrm{CO} 2-2 \mathrm{H} 2 \mathrm{O}$ & & & & 778.4866 & C46 H68 O9 N & 13.5 & & & \\
\hline & $-\mathrm{CO} 2-3 \mathrm{H} 2 \mathrm{O}$ & & & & 760.4766 & C46 H66 O8 N & 14.5 & & & \\
\hline & $-\mathrm{CO} 2-4 \mathrm{H} 2 \mathrm{O}$ & & & & 742.4660 & C46 H64 O7 N & 15.5 & & & \\
\hline & $-\mathrm{CO} 2-5 \mathrm{H} 2 \mathrm{O}$ & & & & 724.5551 & C46 H62 O6 N & 16.5 & & & \\
\hline \multirow[t]{2}{*}{ Group 2} & $-\mathrm{H} 2 \mathrm{O}$ & 672.4085 & C38 H58 O9 N & 10.5 & 672.4094 & C38 H58 O9 N & 10.5 & 672.4088 & C38 H58 O9 N & 10.5 \\
\hline & & 654.3979 & C38 H56 O8 N & 11.5 & 654.3984 & C38 H56 O8 N & 11.5 & & & \\
\hline \multirow[t]{2}{*}{ Group 3} & $-\mathrm{H} 2 \mathrm{O}$ & 462.3198 & $\mathrm{C} 27 \mathrm{H} 44 \mathrm{O} 5 \mathrm{~N}$ & 6.5 & 462.3201 & C27 H44 O5 N & 6.5 & 462.3196 & $\mathrm{C} 27 \mathrm{H} 44 \mathrm{O} 5 \mathrm{~N}$ & 6.5 \\
\hline & & 444.3096 & $\mathrm{C} 27 \mathrm{H} 42 \mathrm{O} 4 \mathrm{~N}$ & 7.5 & 444.3102 & $\mathrm{C} 27 \mathrm{H} 42 \mathrm{O} 4 \mathrm{~N}$ & 7.5 & & & \\
\hline \multirow[t]{2}{*}{ Group 4} & $-\mathrm{H} 2 \mathrm{O}$ & 362.2679 & $\mathrm{C} 22 \mathrm{H} 36 \mathrm{O} 3 \mathrm{~N}$ & 5.5 & 362.2681 & $\mathrm{C} 22 \mathrm{H} 36 \mathrm{O} 3 \mathrm{~N}$ & 5.5 & 362.2681 & $\mathrm{C} 22 \mathrm{H} 36 \mathrm{O} 3 \mathrm{~N}$ & 5.5 \\
\hline & & 344.2574 & $\mathrm{C} 22 \mathrm{H} 34 \mathrm{O} 2 \mathrm{~N}$ & 6.5 & 344.2571 & $\mathrm{C} 22 \mathrm{H} 34 \mathrm{O} 2 \mathrm{~N}$ & 6.5 & & & \\
\hline Group 5 & & 262.1795 & $\mathrm{C} 16 \mathrm{H} 24 \mathrm{O} 2 \mathrm{~N}$ & 5.5 & 262.1794 & $\mathrm{C} 16 \mathrm{H} 24 \mathrm{O} 2 \mathrm{~N}$ & 5.5 & & & \\
\hline Group 6 & & 168.1377 & C10 H18 O N & 2.5 & 168.1378 & C10 H18 O N & 2.5 & & & \\
\hline
\end{tabular}




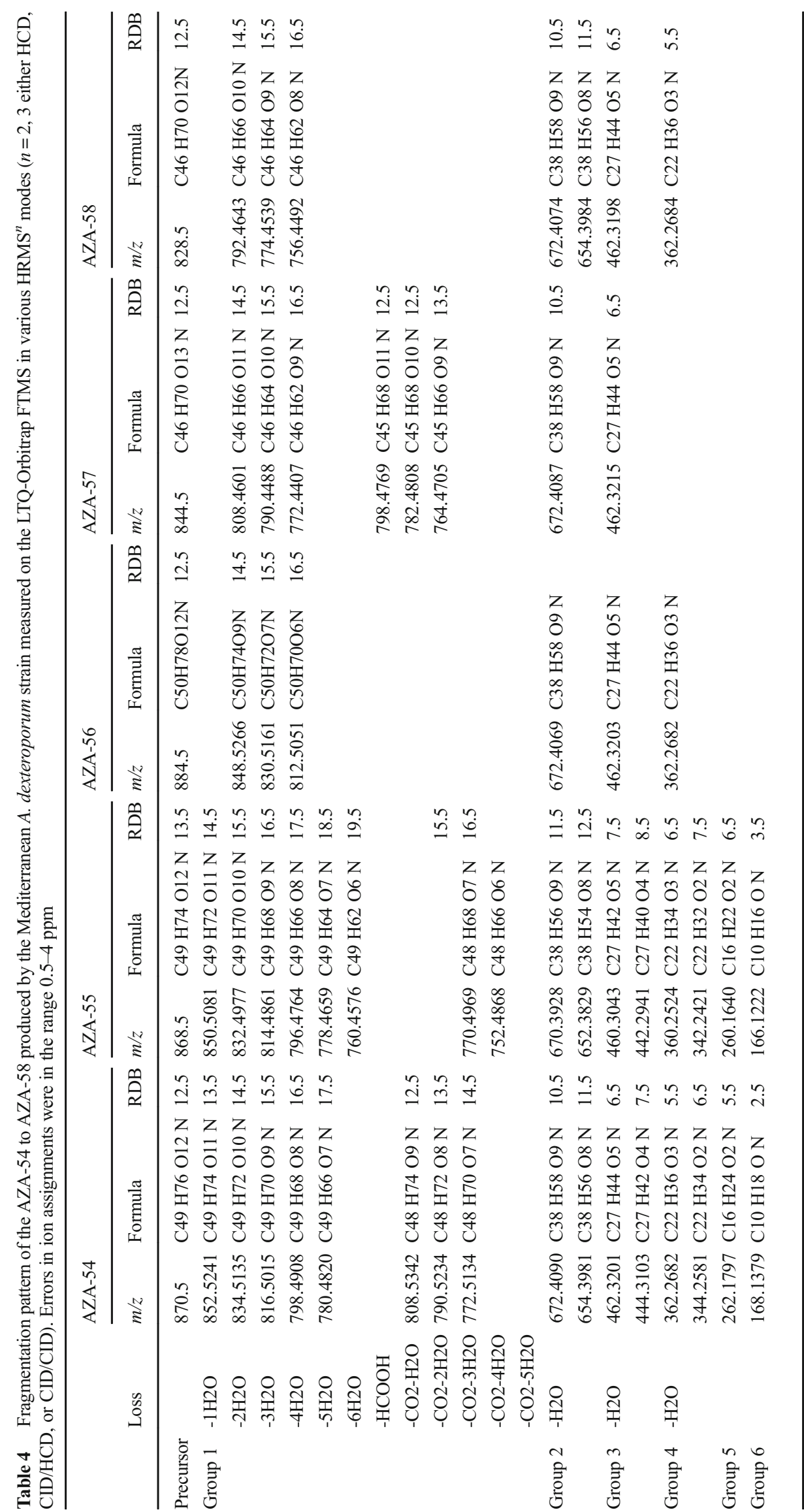


components of the toxin profile (such as AZA-35 and AZA57), the use of CID fragmentation mode was necessary because of its enhanced sensitivity. CID spectra were dominated mainly by group 1 fragments $\left[\mathrm{M}+\mathrm{H}-n \mathrm{H}_{2} \mathrm{O}\right]^{+}(n=1-6)$ and in some cases by the $\left[\mathrm{M}+\mathrm{H}-\mathrm{CO}_{2}-n \mathrm{H}_{2} \mathrm{O}\right]^{+}$ions, with the group 25 fragments presenting very low intensity $(<10 \%$ of the base peak) and the group 6 fragments falling out of the ion stability range (see ESM, Figs. S2 and S3).

SRM experiments on the hybrid triple quadrupole-linear ion trap mass spectrometer excluded the presence of most of the known AZAs (Table 1) in the A. dexteroporum extract. However, product ion scans revealed that six of the seven molecules detected by TOF MS were actually AZA-like compounds sharing the typical AZA group 3-5 fragments at $\mathrm{m} / \mathrm{z}$ 262,362 , and 462 , whereas one compound showed the same pattern, but shifted to $2 \mathrm{Da}$ lower masses. CID spectra of all the seven compounds (Fig. 3) provided some structural information of each individual compound.

Following derivatization with TMSDM, all compounds contained in the A. dexteroporum acetone extract formed the respective methyl esters, with significantly longer retention times (Table 5). This demonstrated the presence of a carboxylic acid functionality in the molecules. The only exception was presented by AZA-56 and AZA-58, which, however, were among the least abundant compounds and possibly just fell below the LOD, as the respective original peaks $(\mathrm{m} / z 884$ and 828 , respectively) disappeared after TMSDM treatment. These results suggested that none of the azaspiracids contained in the A. dexteroporum extract were methyl esters.

The azaspiracids detected in the A. dexteroporum strain SZN-B848 and their fragmentation patterns are discussed below listing them in decreasing order of abundance in the extract and molecular weight (MW). Structural hypotheses are summarized in Fig. 4.

\section{Novel AZA-54 (MW = 869 Da)}

AZA-54 is a new azaspiracid with $[\mathrm{M}+\mathrm{H}]^{+}$at $\mathrm{m} / \mathrm{z} 870$ that represented the major component of the toxin profile of the
Mediterranean A. dexteroporum strain. Compared to AZA-1 $\left(\mathrm{C}_{47} \mathrm{H}_{71} \mathrm{NO}_{12}\right)$, its molecular formula $\left(\mathrm{C}_{49} \mathrm{H}_{75} \mathrm{NO}_{12}\right)$ indicated an elemental increment of $\mathrm{C}_{2} \mathrm{H}_{4}$ in the molecule, whereas the ring double bond equivalents (RDB) of the two molecules were identical (Table 2). Apart from that, AZA-54 showed the same characteristic group 2-6 fragments as AZA-1 in both the CID spectrum (Fig. 3A) obtained on the Q-Trap MS and HRMS $^{n}$ spectra obtained on the LTQ-Orbitrap MS (Table 4). This suggested that the structural difference between AZA-54 and AZA-1 was located in the region C1-C9 (Fig. 4). The elemental increment of $\mathrm{C}_{2} \mathrm{H}_{4}$ could be caused by either the elongation of the side chain of two methylene groups or the presence of one ethyl or two methyl groups or a combination of both. However, the presence of an ion at $\mathrm{m} / \mathrm{z} 808$ followed by two water losses in the CID spectrum of AZA-54 (Fig. 3A) pointed to the loss of $\mathrm{CO}_{2}$ and $\mathrm{H}_{2} \mathrm{O}$ from the pseudomolecular ion. This ion was not as abundant as in the case of 3hydroxylated AZAs ([12], revised structures in [15]) but clearly suggested a change in the substitution pattern in the vicinity of the carboxylic acid functionality. The presence of very weak $\left[\mathrm{M}+\mathrm{H}-\mathrm{CO}_{2}-n \mathrm{H}_{2} \mathrm{O}\right]^{+}$ions $(n=1,2,3)$ was observed also in $\mathrm{HR}$ CID/CID MS ${ }^{3}$ spectra of AZA-54 (Table 4; ESM Fig. S2). Considering that AZA-1, which has a linear side chain, did not eliminate $\mathrm{CO}_{2}$ neither in CID nor in HR CID/ $\mathrm{CID} \mathrm{MS}^{3}$ (Table 3; ESM Fig. S3), the loss of $\mathrm{CO}_{2}$ from the pseudomolecular ion suggested that the simple elongation of the side chain of AZA-54 with two methylene groups was quite unlikely and that some branching of the alkyl chain was instead occurring (Fig. 4). Interestingly, the intensity of the signal at $m / z 808$ in both $\mathrm{CID}(<10 \%$ of the base peak) and HR CID/CID MS ${ }^{3}$ spectra ( $<5 \%$ of the base peak) was much lower than intensity of ions due to $\mathrm{CO}_{2}$ loss in 3-hydroxylated AZAs, likely as a consequence of the different effect on fragmentation of the alkyl group versus the hydroxyl group.

\section{Novel AZA-55 $(\mathrm{MW}=867 \mathrm{Da})$}

This new azaspiracid with $[\mathrm{M}+\mathrm{H}]^{+}$at $m / 2,868$ and molecular formula $\mathrm{C}_{49} \mathrm{H}_{73} \mathrm{NO}_{12}$ was the second most abundant
Table 5 Retention time (Rt) shifts of azaspiracids contained in A. dexteroporum acetone extract on Q-Trap MS

\begin{tabular}{llllll}
\hline & \multicolumn{2}{l}{$\begin{array}{l}{[\mathrm{M}+\mathrm{H}]^{+} \text {and Rt of AZAs in the }} \\
\text { original extract }\end{array}$} & & \multicolumn{2}{l}{$\begin{array}{l}{[\mathrm{M}+\mathrm{H}]^{+} \text {and Rt of AZA methyl esters after }} \\
\text { TMSDM derivatization }\end{array}$} \\
\cline { 2 - 3 } Azaspiracid (AZA) & $m / z$ & $\mathrm{Rt}(\mathrm{min})$ & & $\mathrm{m} / z$ & $\mathrm{Rt}(\mathrm{min})$ \\
\hline AZA-54 & 870 & 12.8 & 884 & 13.3 \\
AZA-55 & 868 & 12.5 & 882 & 13.9 \\
3-epiAZA-7 & 858 & 11.5 & 872 & 12.1 \\
AZA-56 & 884 & 14.8 & 898 & - \\
AZA-57 & 844 & 11.5 & 858 & 12.8 \\
AZA-58 & 828 & 12.1 & 842 & - \\
AZA-35 & 830 & 12.2 & 844 & 13.6 \\
\hline
\end{tabular}


Fig. 4 Structural hypothesis for the seven azaspiracids contained in the Mediterranean A. dexteroporum strain based on the analysis of their fragmentation patterns versus AZA- 1 . The regions of AZA-1 circled in red are those where structural modifications occur

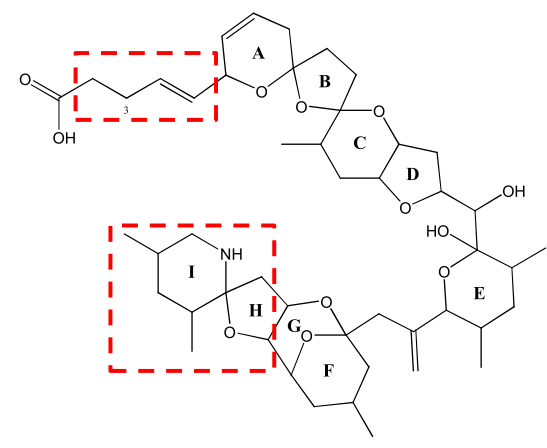

AZA-54: Branching at $\mathrm{C} 2$ or $\mathrm{C} 3$ with $\mathrm{C}_{2} \mathrm{H}_{4}$ (either 2 methyls or 1 ethyl)

AZA-55: 1 double bond in ring $\mathrm{H}$ or $\mathrm{I}$

Branching at $\mathrm{C} 2$ or $\mathrm{C} 3$ with $\mathrm{C}_{2} \mathrm{H}_{4}$ (either 2 methyls or 1 ethyl)

3-epiAZA-7: $1 \mathrm{OH}$ at $\mathrm{C3}$

AZA-56: elongation of the side chain with $\mathrm{C}_{3} \mathrm{H}_{6}$ ( 3 methylenes)

AZA-57: $1 \mathrm{CH}_{2}$ less in the side chain

$1 \mathrm{OH}$ more at $\mathrm{C} 2$ or $\mathrm{C} 3$

AZA-58: $1 \mathrm{CH}_{2}$ less in the side chain

AZA-35: $1 \mathrm{CH}_{2}$ less in the side chain No double bond in the side chain component of the Mediterranean A. dexteroporum strain. It presented two $\mathrm{H}$ less and one unsaturation more than AZA-54 (Table 2). Its fragmentation pattern obtained by CID (Fig. 3B) and HRMS $^{n}$ (Table 4) was almost identical to that of AZA-54 with the only exception that all group 1-6 fragments were downshifted of 2 Da compared to the corresponding fragments of AZA-54. This suggested that AZA-55 contained an additional double bond in ring $\mathrm{H}$ or I. Similarly to AZA-54, very weak $\left[\mathrm{M}+\mathrm{H}-\mathrm{CO}_{2}-n \mathrm{H}_{2} \mathrm{O}\right]^{+}$ ions $(n=3,4)$ were observed also in CID and $\mathrm{HRMS}^{3}$ spectra, suggesting that AZA-55 also presented an alkyl branching in the vicinity of the carboxylic acid functionality. Thus, AZA-55 is an H/I ring unsaturated derivative of AZA-54 (Fig. 4).

\section{Novel 3-epi-AZA-7 (MW = 857 Da)}

The third most abundant component of the Mediterranean A. dexteroporum toxin profile had been tentatively assigned to AZA-7 by Percopo et al. [13]. This compound with $[\mathrm{M}+\mathrm{H}]^{+}$at $\mathrm{m} / \mathrm{z}, 858$ had indeed the same molecular formula $\left(\mathrm{C}_{47} \mathrm{H}_{71} \mathrm{NO}_{13}\right)$ and $\mathrm{RDB}$ value as AZA-7 [5], thus differing from AZA-1 $\left(\mathrm{C}_{47} \mathrm{H}_{71} \mathrm{NO}_{12}\right)$ just by the presence of one additional $\mathrm{O}$ atom. The fragment ions previously detected by in-source fragmentation on TOF MS [13] were all confirmed by CID analysis on the Q-Trap MS (Fig. 3C) and by HR HCD $\mathrm{MS}^{2}$ analysis on the LTQOrbitrap FTMS (Table 3; ESM Fig. S1). In more detail, its fragmentation pattern contained the same characteristic group 2-6 fragments as AZA-1 and AZA-7 [5]. This indicated that the compound at $m / z 858$ shared the B to I ring system with AZA-1 and AZA-7. Thus, compared to AZA-1, both the compound at $m / z, 858$ and AZA-7 have the additional oxygen (likely a hydroxyl group) in the region $\mathrm{C} 1-\mathrm{C} 9$. In contrast to $\mathrm{AZA}-1$, this compound displayed a very complex group 1 fragment cluster characterized by elimination of $\mathrm{CO}_{2}$ and subsequent water losses from the pseudomolecular ion (Fig. 3C, Table 3). These fragments appeared also in the CID MS spectrum of AZA-7 reported by James et al. [5] as minor unassigned fragments at $\mathrm{m} / \mathrm{z} 760$ and $\mathrm{m} / \mathrm{z}$ 742. This clearly suggested that both the compound at $m / z 858$ and AZA-7 were hydroxylated at $\mathrm{C} 3$ (Fig. 4); otherwise, like in most AZAs, the $\mathrm{CO}_{2}$ elimination would not have been observed ([12], revised structures in [15]). However, a comparative LC-HRMS $^{n}$ analysis of the compound at $m / z, 858$ versus a reference sample of AZA-7 isolated from shellfish allowed to exclude the identity of the two compounds based on retention times and relative ratios of the $[\mathrm{M}+$ $\left.\mathrm{H}-\mathrm{nH}_{2} \mathrm{O}\right]^{+}$and $\left[\mathrm{M}+\mathrm{H}-\mathrm{CO}_{2}-\mathrm{nH}_{2} \mathrm{O}\right]^{+}$ions contained in the group 1 fragments. The compound at $\mathrm{m} / \mathrm{z} 858$ eluted 0.55 min later than AZA-7; in addition, group 1 fragments of the former were dominated by the $\left[\mathrm{M}+\mathrm{H}-\mathrm{CO}_{2}-\mathrm{H}_{2} \mathrm{O}\right]^{+}$ ion whereas group 1 fragments of AZA-7 were dominated by $\left[\mathrm{M}+\mathrm{H}-2 \mathrm{H}_{2} \mathrm{O}\right]^{+}$ion (Fig. 5). Such evidence suggested that the $A$. dexteroporum compound was not an unrelated compound but rather a stereoisomer of AZA-7 and that the steric difference is probably located at $\mathrm{C} 3$ because this is the only position that could explain the different intensities of the $\mathrm{CO}_{2}$ losses in both compounds. This is consistent with the compound at $\mathrm{m} / \mathrm{z} 858$ being the epimer at C3 of AZA-7 (3-epi-AZA-7). Noteworthy, the finding of 3-epi-AZA-7 in the Mediterranean A. dexteroporum represents the second case of de novo biosynthesis of a 3hydroxylated AZA in a dinoflagellate, the first case being A. poporum, which can produce AZA-11 [14]. Until recently, 3-hydroxylated AZA were regarded exclusively as shellfish metabolites of AZA-1 and AZA-2 [9].

\section{Novel AZA-56 $(\mathrm{MW}=883$ Da $)$}

AZA-56 is a new azaspiracid with $[\mathrm{M}+\mathrm{H}]^{+}$at $m / z$ 884. Its molecular formula $\left(\mathrm{C}_{50} \mathrm{H}_{77} \mathrm{NO}_{12}\right)$ showed an elemental increment of $\mathrm{C}_{3} \mathrm{H}_{6}$ compared to that of AZA-1 and the same RDB value (Table 2). In CID spectrum (Fig. 3D), AZA-56 showed the same characteristic group 2-6 fragments as AZA-1, most of the fragments being confirmed by $\mathrm{HRMS}^{3}$ analyses (Table 4). This suggested that the additional $\mathrm{C}_{3} \mathrm{H}_{6}$ is located in the region $\mathrm{C} 1-\mathrm{C}$ 9 of $\mathrm{AZA}-1$. The absence of other ions deriving from the further fragmentation of the alkyl chain 
Fig. $5 \mathrm{HR}$ CID/CID MS ${ }^{3}$ spectra of $\mathbf{A}$ the shellfish metabolite AZA-7 and B the 3-epiAZA-7 contained in the Mediterranean A. dexteroporum extract.

Expansion of the mass region $\mathrm{m} / \mathrm{z}$ 700-900 where group 1 fragments appear including $[\mathrm{M}+\mathrm{H}-$ $\left.n \mathrm{H}_{2} \mathrm{O}\right]^{+}$ions (in blue) and $[\mathrm{M}+\mathrm{H}-$ $\left.\mathrm{CO}_{2}-n \mathrm{H}_{2} \mathrm{O}\right]^{+}$ions (in red)
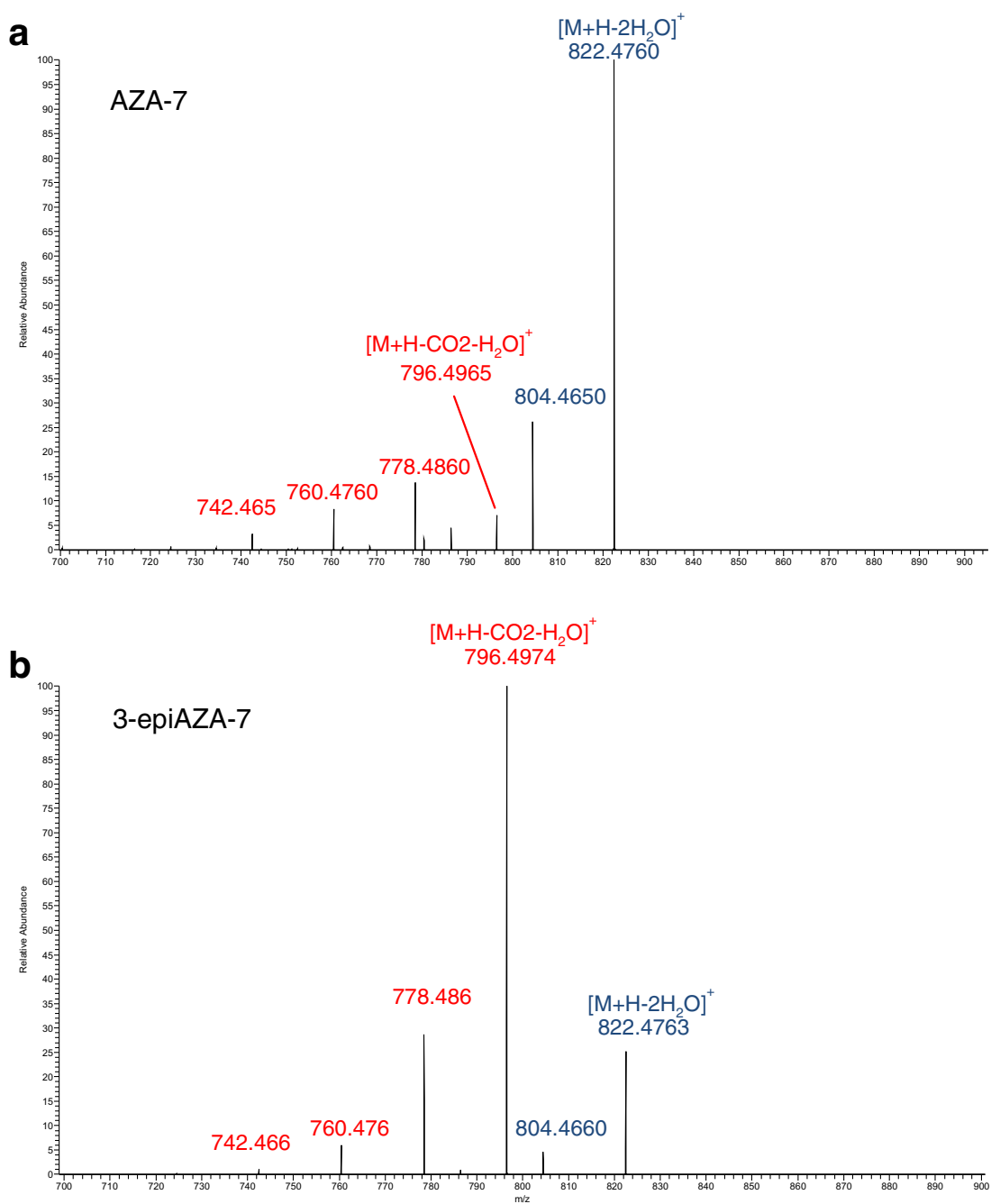

(e.g., the elimination of $\mathrm{CO}_{2}$ from the pseudomolecular ion and subsequent water losses) suggested that elongation of the side chain of three methylene groups occurs in AZA-56 (Fig. 4).

\section{Novel AZA-57 (MW = 843 Da)}

AZA-57 is a new azaspiracid with $[\mathrm{M}+\mathrm{H}]^{+}$at $m / z \quad 844$ and a minor component of the Mediterranean A. dexteroporum toxin profile. Its molecular formula $\left(\mathrm{C}_{46} \mathrm{H}_{69} \mathrm{NO}_{13}\right)$ contained one $\mathrm{O}$ atom more and one methylene group less than AZA-1 and presented its same RDB value (Table 2). The CID spectrum (Fig. 3E) contained the same group 25 fragments as AZA-1, with group 2 and 3 fragments being confirmed also by $\mathrm{HRMS}^{n}$ spectra (Table 4). This suggested that the structural modifications in AZA-57 occur in the region $\mathrm{C} 1-\mathrm{C} 9$ of AZA-1. Furthermore, the fragmentation pattern was dominated by the loss of $\mathrm{CO}_{2}$ and consequent water losses from the pseudomolecular ion (Table 4), which could suggest that AZA-57 is a 3- hydroxylated derivative of AZA-1. However, a fragment ion at $m / z, 798.4769$ was also present, which corresponded to $[\mathrm{M}+\mathrm{H}-\mathrm{HCOOH}]^{+}$and had never been observed before in any AZA fragmentation spectrum. On the whole, these results suggested that AZA-57 lacks one methylene in the side chain and is hydroxylated in close proximity of the carboxylic group, which could be either $\mathrm{C} 2$ or $\mathrm{C} 3$, the latter resulting in an enol functionality (Fig. 4). However, the exact position of the hydroxylation cannot be determined by MS alone because this is an unprecedent case.

Another compound contained at trace levels in the extract eluted about 3 min later than AZA-57 $(\mathrm{Rt}=$ $13.18 \mathrm{~min}$ on system \#2) and had the same nominal mass as AZA-57 but a different elemental composition ([M+ $\mathrm{H}]^{+}$ion at $m / z$ 844.5202, $\mathrm{RDB}=11.5, \mathrm{C}_{47} \mathrm{H}_{74} \mathrm{NO}_{12}, \Delta=$ $-0.418 \mathrm{ppm})$. Due to low abundance, the $\mathrm{HRMS}^{3}$ spectrum contained just the group 1 and 3 fragments suggesting it is an azaspiracid but hampering further structural hypotheses. 


\section{Novel AZA-58 (MW = 827 Da $)$}

AZA-58 is a new azaspiracid with $[\mathrm{M}+\mathrm{H}]^{+}$at $m / z 828$ which had been tentatively assigned to AZA-3 in Percopo et al. [13], having the same molecular formula $\left(\mathrm{C}_{46} \mathrm{H}_{69} \mathrm{NO}_{12}\right)$ and exact mass. However, AZA-58 eluted at a different retention time than AZA-3 and had a different structure as revealed by its fragmentation pattern (Fig. 3F, Table 4). Indeed, AZA-58 showed group 2 and 3 fragments identical to AZA-1 $(\mathrm{m} / z$ 672 and 462, respectively) and different from AZA-3 $(\mathrm{m} / \mathrm{z}$ 658 and 448, respectively), whereas the group 4 fragment $(\mathrm{m} / \mathrm{z}, 362)$ was identical for all the three molecules. This fragmentation suggested that AZA-58 differed from AZA-1 just by the lack of a methylene group in the region $\mathrm{C} 1-\mathrm{C} 9$. We can confidently exclude the lack of a methylene group in the ring A since this would lead to group 2 fragments different from AZA-1. Therefore, most likely AZA-58 lacks one methylene in the alkyl chain (either $\mathrm{C} 2$ or $\mathrm{C} 3$ ), thus being the normethylene derivative of AZA-1 (Fig. 4).

\section{AZA-35 (MW = 829 Da)}

The compound with $[\mathrm{M}+\mathrm{H}]^{+}$at $m / z, 830$ represents a very minor component of the Mediterranean A. dexteroporum toxin profile. The molecular formula $\left(\mathrm{C}_{46} \mathrm{H}_{71} \mathrm{NO}_{12}\right)$ contained just two $\mathrm{H}$ atoms more than that of AZA-58 and is the same as that of AZA-38 from Amphidoma languida (compound 3 reported by Krock et al. [12]). Based on the fragmentation pattern contained in its CID spectrum (Fig. 3G) and $\operatorname{HRMS}^{n}(n=2-$ 3) spectra (Table 3), we excluded that this compound was AZA-38 since it lacked the characteristic group 2-5 fragments at $m / z 686,448,348$, and 248 of the latter. On the contrary, this compound presented the same group 2-5 fragments as AZA-1 and AZA-58, which suggested that, similarly to AZA-58, it presented the same B to I ring systems as AZA-1 and thus lacked a methylene group in the region $\mathrm{C} 1-\mathrm{C}$ 9. The structural modification must be located in the methylene chain $(\mathrm{C} 2-\mathrm{C} 3)$ for the same reasons discussed for AZA-58. In addition, this compound also presented group 2-5 fragments identical to AZA-58 and AZA-1 but a lower RDB value (11.5 versus 12.5 of AZA-1 and AZA-58), which suggested that in this molecule the double bond either in the side chain or in the A ring was saturated. The latter hypothesis could be excluded. Indeed AZA-37, which has a saturated A ring ([12], revised structures in [15]), produces group 2 fragments due to elimination of a $\mathrm{C} 7$ part structure, which results from a simultaneous cleavage between $\mathrm{C} 6$ and its adjacent oxygen and between $\mathrm{C} 7$ and $\mathrm{C} 8$, and not between $\mathrm{C} 9$ and $\mathrm{C} 10$ as occurring in AZA-1 (Fig. 1), in AZA-58, as well as in AZA-35. The whole of these observations suggested that this compound, compared to AZA-1, presented one methylene less and one double bond less in the side chain, thus being the saturated form of AZA-58 (Fig. 4). Recently, Kilkoyne et al. [29] have reported AZA-35 from A. spinosum having the same molecular formula and fragmentation behavior as the compound we detected. Availability of an A. spinosum extract containing AZA-35 allowed us to confirm the identity of this compound as AZA-35 based on retention time (system \#2) and HR CID/ $\mathrm{CID} \mathrm{MS}^{3}$ data, suggesting that AZA-35 is the nor-methylene 4,5-dehydroAZA-1.

\section{Quantitative analyses}

The relative abundances of the AZAs detected in the Mediterranean strain of $A$. dexteroporum were determined in decreasing order as follows: $65.3 \%$ of AZA- $54,18.0 \%$ of AZA-55, $14.9 \%$ of 3 -epiAZA-7, $0.6 \%$ of AZA- $58,0.5 \%$ of AZA-35, $0.3 \%$ of AZA-57, and $0.2 \%$ of AZA-56 (Fig. 6). The quantification was based on the SRM mass transitions between the pseudomolecular mass and the first water loss of each AZA (Table 1) on the reasonable assumption that the ratios of these transitions are similar among all AZAs. Nevertheless, it has to be taken into account that this quantification is only a good approximation since the exact molecular responses of the individual AZAs of this strain are still unknown. However, it is clear that the AZA profile of the Mediterranean strain of $A$. dexteroporum is dominated by AZA-54 making up approximately two thirds of total AZAs. The second most abundant component is AZA-55, which differs from AZA-54 only by an additional unsaturation in the ring H/I. This means that the AZA profile of A. dexteroporum is dominated for over $80 \%$ by compounds with an alkyl branching (AZA-54 and AZA-55), a structural feature completely absent in other AZA-producing species. Also the third most abundant 3-epi-AZA-7 has never been observed in dinoflagellates. The other four AZAs of the Mediterranean A. dexteroporum together only made up less than $2 \%$ and accordingly can be regarded as minor compounds.

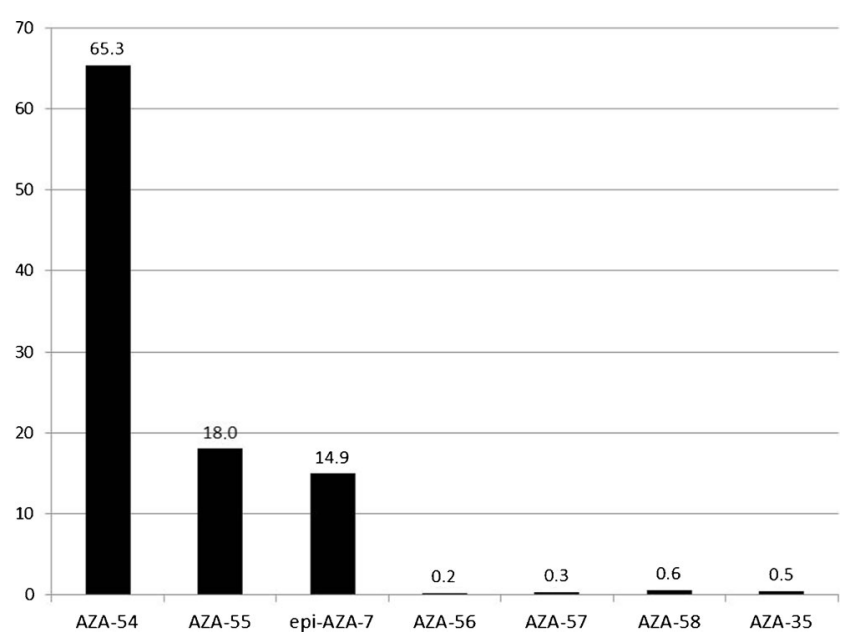

Fig. 6 Relative abundance of the seven azaspiracids produced by the Mediterranean strain of $A$. dexteroporum expressed in percent 


\section{Conclusions}

This study confirmed the Mediterranean A. dexteroporum as an azaspiracid-producing species and provided a better characterization of the three molecules initially detected [13] in the strain, along with the demonstration of the presence of at least seven azaspiracids. The three compounds at $\mathrm{m} / z, 828,830$, and 858 initially hypothesized by Percopo et al [13] to be AZA-3 [7], compound 3 [12], and AZA-7 [5], respectively, were proven to be different compounds, two of which were so far undescribed. Based on retention time, exact masses, and fragmentation patterns, six out of the seven AZAs produced by the Mediterranean A. dexteroporum strain proved to be new molecules (3-epi-AZA-7, AZA-54 to AZA-58) and one was a previously reported compound (AZA-35). This is the first time that an epimer of the shellfish metabolite AZA-7 is reported in a dinoflagellate extract and that AZA-35 is reported in an Azadinium species other than A. spinosum [29]. Overall, the results obtained in this study show that MS and fragmentation behavior of AZAs on different LC-MS systems may produce complementary data on these molecules, which allow to characterize them reliably.

All the molecules studied in this work, except AZA-55, seem to have the same A to I-ring system as AZA-1, suggesting that the differences among these molecules are all located in the carboxylic side chain. Recently, four new compounds were discovered in Amphidomataceae, all showing the same CID fragmentation patterns with a conserved E-I ring system in common [12]. All this evidence suggests that Amphidomataceae have similar biosynthetic pathways that produce molecules with a relatively conserved polyketide skeleton [30] and a more variable part towards the carboxylic end. Branching of the side chain observed in AZA-54 and AZA-55 has never been observed in any known azaspiracid and proved to cause low abundance of $\mathrm{CO}_{2}$ loss $(<10 \%)$ in contrast to 3-hydroxylation which results in a highly abundant $\mathrm{CO}_{2}$ loss.

It is worth noting that 3-hydroxylated AZAs have been long thought to be shellfish metabolites of AZA-1 and AZA-2 resulting from enzymatic hydroxylation in the shellfish at C3 [5, 9]. However, recently, Krock et al. [15] found the 3-hydroxylated derivatives AZA-36 and AZA-37 to be de novo synthesized in A. poporum strains from the North Sea and Korea, respectively. In addition, some strains of $A$. poporum from the Northwest Pacific region only produced AZA-11, the 3-hydroxylated derivative of AZA-2, without producing AZA-2 itself [14]. Interestingly, also the Mediterranean A. dexteroporum produces 3-epi-AZA-7, the 3-hydroxylated derivative of AZA-1 without producing AZA-1 itself. So, our results show that the Mediterranean A. dexteroporum is another species that can produce de novo 3-hydroxylated AZAs which further supports the hypothesis that in some Amphidomataceae an enzymatic pathway leading to 3hydroxylation exists.

The molecules found in the Mediterranean A. dexteroporum strain further add to the number of so far known AZAs directly produced by microalgae, whereas the majority of the known AZAs is still considered to be transformation products within shellfish. Compared to other Amphidomataceae species, for which only a few azaspiracids have been reported, the diversity of AZAs in the Mediterranean A. dexteroporum strain seems to be exceptional. However, a high diversity of AZAs is now also known from A. spinosum [17, 29] and future studies using the multi-platform approach or computational approaches such as molecular networking [31] might show this for other species/strains as well. The presence of so many AZAs is even more surprising if compared to the complete absence of AZAs in the Arctic strain of the same species [27], although cases of intraspecific differences in toxin profiles are widespread [14, 32].

Recent studies on the toxicity of some purified AZA analogues relative to AZA-1 showed that all analyzed AZAs were toxic and that AZA-2, AZA-3, and AZA-6 were more toxic than AZA-1 by 8.3, 4.5, and 7 times, respectively [10], 37-epi-AZA-1 was 5 times more toxic [11], AZA-33 and AZA-34 were 5 times less toxic and 5 times more toxic, respectively [17], and AZA-36 and AZA-37 were 6 and 3 times less toxic, respectively [15]. As major differences in toxicity can be related to slightly different structures of AZAs, the actual toxicity of the different compounds produced by the Mediterranean A. dexteroporum is worthy of consideration in future toxicological studies. In the meantime, for a correct evaluation of the AZA-related risk in the Mediterranean area, the presence of the azaspiracids produced by A. dexteroporum should be taken into account in the monitoring programs of these marine biotoxins. This seems even more important considering that none of the AZAs currently legislated (AZA-1, AZA-2, and AZA-3) and hence regularly monitored in shellfish is actually produced by this strain.

Acknowledgments The authors are deeply grateful to Dr Jane Kilkoyne (Marine Institute, Galway, Ireland) for providing a reference sample of AZA-7 and an A. spinosum extract containing AZA-35 and to Dr Philipp Hess (Ifremer, Nantes, France) for providing a mussel tissue extract containing AZA-1, AZA-2, and AZA-3.

Compliance with ethical standard This paper does not raise any concern regarding human and animal rights and does not involve animals or humans.

Conflict of interests There is no conflict of interest pending on this paper. 


\section{References}

1. McMahon T, Silke J. West coast of Ireland; winter toxicity of unknown aetiology in mussels. Harmful Algae News. 1996;14:2.

2. Satake M, Ofuji K, James KJ, Furey A, Yasumoto T. New toxic event caused by Irish mussels. In: Reguera B, Blanco J, Fernandez ML, Wyatt T, editors. Harmful Algae. Spain: Xunta de Galicia and Intergovernmental Oceanographic Commission of UNESCO; Santiago de Compostela, 1998. p. 468-9.

3. Satake M, Ofuji K, Naoki H, James KJ, Furey A, McMahon T, et al. Azaspiracid, a new marine toxin having unique spiro ring assemblies, isolated from Irish mussels, Mytilus edulis. J Amer Chem Soc. 1998;120:9967-8.

4. Nicolaou KC, Chen DYK, Li Y, Qian W, Ling T, Vyskocil S, et al. Total synthesis of the proposed azaspiracid-1 structure, part 2: coupling of the $\mathrm{C} 1-\mathrm{C} 20, \mathrm{C} 21-\mathrm{C} 27$, and $\mathrm{C} 28-\mathrm{C} 40$ fragments and completion of the synthesis. Angew Chem. 2003;115:3777-81.

5. James KJ, Moroney C, Roden C, Satake M, Yasumoto T, Lehane $\mathrm{M}$, et al. Detection of five new hydroxyl analogues of azaspiracids in shellfish using multiple tandem mass spectrometry. Toxicon. 2003:41:145-54.

6. Tillmann U, Elbrächter M, Krock B, John U, Cembella A. Azadinium spinosum gen. et sp. nov. (Dinophyceae) identified as a primary producer of azaspiracid toxins. Eur J Phycol. 2009;44:63-79.

7. Ofuji K, Satake M, McMahon T, Silke J, James KJ, Naoki H, et al. Two analogs of azaspiracid isolated from mussels, Mytilus edulis, involved in human intoxication in Ireland. Nat Toxins. 1999;7:99-102.

8. Ofuji K, Satake M, McMahon T, James KJ, Naoki H, Oshima Y, et al. Structures of azaspiracid analogs, azaspiracid-4 and azaspiracid-5, causative toxins of azaspiracid poisoning in Europe. Biosci Biotechnol Biochem. 2001;65:740-2.

9. Rehmann N, Hess P, Quilliam MA. Discovery of new analogs of the marine biotoxin azaspiracid in blue mussels Mytilus edulis by ultra-performance liquid chromatography/tandem mass spectrometry. Rapid Commun Mass Spectrom. 2008;22:549-58.

10. Kilcoyne J, Keogh A, Clancy G, LeBlanc P, Burton I, Quilliam $\mathrm{MA}$, et al. Improved isolation procedure for azaspiracids from shellfish, structural elucidation of azaspiracid-6, and stability studies. J Agric Food Chem. 2012;60:2447-55.

11. Kilcoyne J, McCarron P, Twiner MJ, Nulty C, Wilkins AL, Rise F, et al. Epimers of azaspiracids: isolation, structural elucidation, relative LC-MS response, and in vitro toxicity of 37-epi-azaspiracid-1 . Chem Res Toxicol. 2014a;27:587-600.

12. Krock B, Tillmann U, Voß D, Koch BP, Salas R, Witt M, et al. New azaspiracids in Amphidomataceae (Dinophyceae). Toxicon. 2012;60:830-9.

13. Percopo I, Siano R, Rossi R, Soprano V, Sarno D, Zingone A. A new potentially toxic Azadinium species (Dinophyceae) from the Mediterranean Sea, A. dexteroporum sp. nov. J Phycol. 2013;49: 950-66.

14. Krock B, Tillmann U, Witt M, Gu H. Azaspiracid variability of Azadinium poporum (Dinophyceae) from the China Sea. Harmful Algae. 2014;36:22-8.

15. Krock B, Tillmann U, Potvin É, Jeong HJ, Drebing W, Kilcoyne J, et al. Structure elucidation and in vitro toxicity of new azaspiracids isolated from the marine dinoflagellate Azadinium poporum. Mar Drugs. 2015;13:6687-702.

16. Tillmann U, Borel CM, Barrera F, Lara R, Krock B, Almandoz GO, et al. Azadinium poporum from the Argentine Continental Shelf, Southwestern Atlantic, produces azaspiracid-2 and azaspiracid-2 phosphate. Harmful Algae. 2016;5:40-55.

17. Kilcoyne J, Nulty C, Jauffrais T, McCarron P, Herve F, Foley B, et al. Isolation, structure elucidation, relative LC-MS response, and in vitro toxicity of azaspiracids from the dinoflagellate Azadinium spinosum. J Nat Prod. 2014b;77:2465-74.

18. Jauffrais T, Herrenknecht C, Séchet V, Sibat M, Tillmann U, Krock B, et al. Quantitative analysis of azaspiracids in Azadinium spinosum cultures. Anal Bioanal Chem. 2012;403:833-46.

19. Hess P, McCarron P, Krock B, Kilcoyne J, Miles CO. Azaspiracids: chemistry, biosynthesis, metabolism, and detection. In: Botana LM, editor. Seafood and freshwater toxins: pharmacology, physiology, and detection, Third Edition. Florida: CRC Press, Taylor \& Francis Group; Boca Raton; 2014. p. 799-822.

20. Twiner MJ, Rehmann N, Hess P, Doucette GJ. Azaspiracid shellfish poisoning: a review on the chemistry, ecology, and toxicology with an emphasis on human health impacts. Mar Drugs. 2008;6:39-72.

21. Anon. Commission regulation (EU) No 15/2011 of 10 th January 2011 amending Regulation (EC) No 2074/2005 as regards recognized testing methods for detecting marine biotoxins in live bivalve molluses L6/3-6. 2011.

22. EU-Harmonised Standard Operating Procedure for determination of lipophilic marine biotoxins in molluses by LC-MS/MS, Version 5, 2015. http://a esan.mssi.gob. es/en/CRLMB/web/procedimientos_crlmb/crlmb_standard_ operating_procedures.shtml.

23. Brombacher S, Edmonds S, Volmer DA. Studies on azaspiracid biotoxins. II. Mass spetral behavior and structural elucidation of azaspiracid analogs. Rapid Commun Mass Spectrom. 2002;16: 2306-16.

24. Hamilton B, Díaz Sierra M, Lehane M, Furey A, James KJ. The fragmentation pathways of azaspiracids elucidated using positive nanospray hybrid quadrupole time-of-flight (QqTOF) mass spectrometry. An International Journal. 2004;18:355-62.

25. Volmer DA, Brombacher S, Whitehead B. Studies on azaspiracid biotoxins. I. Ultrafast high-resolution liquid chromatography/mass spectrometry separations using monolithic columns. Rapid Commun Mass Spectrom. 2002;16:2298-305.

26. Gu H, Luo Z, Krock B, Witt M, Tillmann U. Morphology, phylogeny and azaspiracid profile of Azadinium poporum (Dinophyceae) from the China Sea. Harmful Algae. 2013;21-22:64-75.

27. Tillmann U, Gottschling M, Nézan E, Krock B. First records of Amphidoma languida and Azadinium dexteroporum (Amphidomataceae, Dinophyceae) from the Irminger Sea off Iceland. Marine Biodiversity Records. 2015;8:142. doi:10.1017 /S1755267215001128.

28. Quilliam MA, Hess P, Dell'Aversano C. Recent developments in the analysis of phycotoxins by liquid chromatography-mass spectrometry. In: de Koe WJ, Samson RA, van Egmond HP, Gilbert J, Sabino M, editors. Mycotoxins and phycotoxins in perspective at the turn of the millennium. 2001. p. 383-91.

29. Kilcoyne J, Nulty C, McCarron P, Jauffrais T, Twiner M, Quilliam $\mathrm{MA}$, et al. Isolation of minor and novel azaspiracids - structure elucidation and toxicology. Toxicon. 2014;91:172.

30. Meyer JM, Rödelsperger C, Eichholz K, Tillmann U, Cembella A, McGaughran A, et al. Transcriptomic characterisation and genomic glimpse into the toxigenic dinoflagellate Azadinium spinosum, with emphasis on polyketide synthase genes. BMC Genomics. 2015;16:27.

31. Teta R, Dellasala G, Glukhov E, Gerwick L, Gerwick WH, Mangoni A, et al. Combined LC-MS/MS and molecular networking approach reveals new cyanotoxins from the 2014 cyanobacterial bloom in Green Lake, Seattle. Environ Sci Technol. 2015;49(24):14301-10.

32. Burkholder JM, Gilbert PM. Intraspecific variability: an important consideration in forming generalizations about toxigenic algal species. S African J Mar Sci. 2006;28:177-80. 